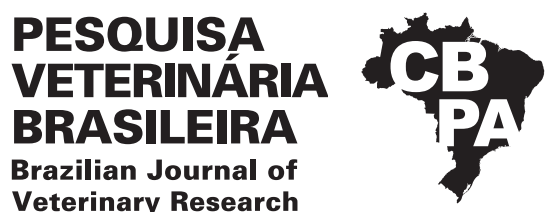

Pesq. Vet. Bras. 41:e06845, 2021

DOI: $10.1590 / 1678-5150-P V B-6845$

Original Article

Veterinarv Research

ISSN 0100-736X (Print)

ISSN 1678-5150 (Online)

\title{
Ultrasound with laparoscopy for the diagnosis of abdominal disorders in cattle ${ }^{1}$
}

\author{
José Ricardo B. Silva² ${ }^{\text {DD }}$, José Augusto B. Afonso ${ }^{3}$, Carla L. Mendonça ${ }^{3}$, \\ Jobson Filipe P. Cajueiro ${ }^{3}$, Juliana M. Alonso² (D), Uila A.A. Alcântara ${ }^{3}$, \\ Rodolpho A. Rebouças ${ }^{3}$ (D) and Celso Antônio Rodrigues ${ }^{2 *}$ (D)
}

\begin{abstract}
Silva J.R.B., Afonso J.A.B., Mendonça C.L., Cajueiro J.F.P., Alonso J.M., Alcântara U.A.A., Rebouças R.A. \& Rodrigues C.A. 2021. Study of ultrasound with laparoscopy for the diagnosis of abdominal disorders in cattle. Pesquisa Veterinária Brasileira 41:e06845, 2021. Faculdade de Medicina Veterinária e Zootecnia, Universidade Estadual Paulista "Júlio de Mesquita Filho", Rua Prof. Dr. Walter Maurício Correa s/n, Cx. Postal 560, Distrito de Rubião Júnior, Botucatu, SP 18618-682, Brazil. E-mail: celso.a.rodrigues@unesp.br

This study aimed to evaluate laparoscopy with abdominal ultrasound exams to establish accurate diagnosis and prognosis. The experimental design was a prospective clinical study. Nine adult crossbred bovines suffering from abdominal disorders were admitted to the cattle clinic for clinical examinations. Abdominal ultrasound was carried out, and complete blood counts were performed. Subsequently, exploratory laparoscopy was performed. After surgery (exploratory laparoscopy on the right or left side), animals with a severe prognosis or untreatable clinical condition were euthanised and necropsied. During laparoscopy, circumscribed reticuloperitonitis could not be detected, nor could other abnormalities in the cranioventral region of the abdomen previously observed on ultrasound and confirmed during necropsy. However, alterations due to peritoneal damage, such as adhesions, were observed dorsally in addition to alterations in macroscopic aspects of the peritoneal fluid. Exploratory standing laparoscopy through the paralumbar fossae may constitute a supplementary procedure for diagnosing abdominal disorders in cattle, but it is not suitable in cases of diseases characterised by focal lesions concentrated in the cranioventral region of the abdomen. When associated with clinical, laboratory, and ultrasound examinations, this technique may improve the accurate diagnosis and prognosis of abdominal disorders in cattle.
\end{abstract}

INDEX TERMS: Ultrasound, laparoscopy, diagnosis, abdominal disorders, cattle, bovine, digestive diseases, reticuloperitonitis, ultrasonography.

\begin{abstract}
RESUMO.- [Estudo da ultrassonografia e laparoscopia para diagnóstico das desordens abdominais em bovinos.] Este estudo teve como objetivo avaliar a laparoscopia com exames de ultrassom abdominal para estabelecer um diagnóstico e prognóstico precisos. 0 desenho experimental foi um estudo clínico prospectivo. Nove bovinos adultos mestiços com distúrbios abdominais foram utilizados. Os
\end{abstract}

\footnotetext{
${ }^{1}$ Received on December 19, 2020.

Accepted for publication on January 15, 2021.

${ }^{2}$ Faculdade de Medicina Veterinária e Zootecnia (FMVZ), Universidade Estadual Paulista "Júlio de Mesquita Filho" (Unesp), Rua Prof. Dr. Walter Maurício Correa s/n, Cx. Postal 560, Distrito de Rubião Júnior, Botucatu, SP 18618-682, Brazil. *Corresponing author: celso.a.rodrigues@unesp.br

${ }^{3}$ Clínica de Bovinos, Universidade Federal Rural de Pernambuco (UFRPE), Campus Garanhuns, Av. Bom Pastor s/n, Cx. Postal 152, Boa Vista, Garanhuns, PE 55292-270, Brazil.
}

bovinos admitidos na Clínica de Bovinos foram submetidos a exame clínico, adicionalmente foram realizadas hemograma e ultrassonografia abdominal. Posteriormente, foi realizada laparoscopia exploratória. Após a cirurgia (laparoscopia exploratória no lado direito ou esquerdo), nove animais com manifestações clínicas graves e intratáveis foram sacrificados e necropsiados. Durante a laparoscopia, não foi possível detectar reticuloperitonite circunscrita, bem como outras anormalidades na região crânio-ventral do abdome, previamente observadas na ultrassonografia e confirmadas durante a necropsia. No entanto, alterações devido a dano peritoneal, como aderências, foram observadas dorsalmente. É possível que a laparoscopia exploratória em apoio quadrupedal através da fossa paralombar constitua um procedimento complementar para o diagnóstico de distúrbios abdominais em bovinos, embora não seja adequado em casos 
de doenças caracterizadas por lesões focais concentradas na região cranioventral do abdome. Quando associada a exames clínicos, laboratoriais e de ultrassom, essa técnica pode melhorar o diagnóstico e prognóstico preciso dos distúrbios abdominais em bovinos.

TERMOS DO INDEXAÇÃO: Ultrassonografia, laparoscopia, diagnóstico, desordens abdominais, bovinos, doenças digestivas, reticuloperitonite.

\section{INTRODUCTION}

During physical examination, additional tests are often needed to confirm clinical suspicions, to support a prognosis/diagnosis and determine the feasibility of surgical intervention, and to determine clinical severity (Dirksen 1993). The clinical examination methods used for abdominal disorders in cattle include ultrasound, which is non-invasive, has a low operational cost and can be performed on the farm, and diagnostic laparotomy, which is a surgical procedure that involves costs, including those related to the convalescence period, prolonged disposal of milk due to the presence of antimicrobial residues, and considerable surgical trauma. In addition, convincing the owner of the need for this procedure can be difficult (Braun 2005).

Minimally invasive surgical approaches are facilitating beneficial changes in the field of veterinary medicine. Although they do not completely replace conventional surgical methods, minimally invasive approaches are becoming increasingly popular in the modern surgical 'arsenal' because they are innovative and very advantageous for diagnostic and therapeutic surgical procedures (Bouré 2005). The advantages of laparoscopic surgery include small incisions, reduced tissue trauma, less discomfort and pain in the postoperative period, shorter hospitalisation time, faster postoperative recovery, and better cosmetic results (Lau et al. 1997, Bouré 2005, Silva 2015).

In human patients, there is strong scientific evidence that laparoscopy provides better diagnostic accuracy than ultrasound in acute abdominal symptoms (Stefanidis et al. 2009), pelvic pain (Bharwani \& Jain 2017) and peritonitis (Agresta et al. 2006). Laparoscopy can be used both to inform the diagnosis and implement treatments, thereby reducing the number of non-treatment laparotomies and the related complications. The only contraindication for laparoscopy is the presence of evident signs of a viscus perforation (free gas in the abdominal cavity and haemodynamic instability). Thus, in most instances, laparoscopy can be used to clarify the clinical conditions and can prevent unnecessary conventional laparotomy, and the time involved in laparoscopy appears to be well spent in avoiding the risks associated with conventional laparotomy.

The use of minimally invasive surgeries using rigid endoscopy in cattle has been reported, and many approaches can be performed with the patient in standing position, without general anaesthesia, as in the treatment of abomasum displacement (Van Leeuwen et al. 2000, Janowitz 2001, Mulon et al. 2006, Perotta et al. 2017), in which endoscopy resulted in faster recovery compared to omentopexy via right flank laparotomy (Wittek et al. 2009). Moreover, successful treatments have been reported with the use of rigid endoscopy in bilateral ovariectomy via left flank access in a standing position (Bleul et al. 2005), in kidney biopsy in standing steers (Chiesa et al. 2009), in laparoscopic cryptorchidectomy in standing bulls (Kaneko et al. 2015), in evaluating umbilical diseases in calves (Robert et al. 2016), and in a comparison of tenotomy versus teloscopy for treating teat diseases (Hirsbrunner et al. 2001). In addition, the use of flexible endoscopic equipment in abdominal exploration was attempted (1984). Nevertheless, there remains a need for studies about the diagnostic applications and accuracy of laparoscopic methods for comparison with other wellestablished diagnostic techniques as such ultrasonography with the aim of minimising non-treatment laparotomies.

Our hypothesis is that laparoscopic surgery is a useful complement exam to ultrasonography for diagnosing abdominal disorders in cattle. Thus, the objective of this study was to study laparoscopy and abdominal ultrasound with complementary exams to establish an accurate diagnosis and prognosis.

\section{MATERIALS AND METHODS}

Animals/clinical assessment. The project was approved by the Ethics Committee on Animal Use (CEUA) of the "Universidade Federal Rural de Pernambuco" (UFRPE) under protocol 135/2016 and the CEUA of the "Faculdade de Medicina Veterinária e Zootecnia", "Universidade Estadual Paulista 'Júlio de Mesquita Filho'” (FMVZUNESP) under protocol 124/2016.

The study included nine crossbred (Holstein X Zebu) bovines raised in the southern wasteland of Pernambuco state, Brazil. The animals were 1.5 to 10 years of age (median 6.2 years) and included eight females and one male raised in a semi-intensive management system and fed a diet consisting of native grassland, corn silage, concentrates, and forage palm (Opuntia ficus indica). These animals underwent clinical examinations according to Dirksen (1993), and clinical, haematologic, ultrasonographic, laparoscopic, and postmortem findings were recorded in their respective medical records. Only animals with primary disease located in the digestive system were included.

Ultrasound examination. Ultrasound examination was performed routinely before surgery (Braun 2005) (Mindray, model Z6, São Paulo, Brazil) using a 3.5-Mhz convex transducer, with animals in the standing position to locate the main lesions and to estimate the clinical severity. The area delineated by the fourth intercostal space bilateral to the paralumbar fossae and ventral to the region from the fifth intercostal space to the udder or prepuce and dorsally was identified bilaterally to the point where the shoulder joins the thorax and caudally to the last rib. The area of the abdominal cavity was clipped, and ultrasound gel was used. The exam began in the left cranioventral region, following the left side (caudo-cranial direction) and ending on the right side. During the examination, the reticulum motility and the presence of adhesions between the reticulum and adjacent organs were investigated by measuring displacement from the abdominal cavity floor in a cranial-dorsal direction during biphasic contraction. Impaired motility was identified by observing hyperechoic adhesions adjacent to the reticulum, and the abdominal cavity was explored for the presence of multiple fibrin deposits, intraabdominal fluid, abscesses, altered organ position, and thickening of the intestinal wall. A scan was performed through the surgical sites used for laparoscopy, and the thickness of the abdominal wall was measured on the right and left sides.

Exploratory laparoscopy. Exploratory laparoscopy was performed for all the animals after solid food fasting for 24 hours prior to the surgery. The animals were maintained in a standing position under physical restraint with ropes in a cattle crush without sedation. Routine surgical preparation of the operative 
field was carried out before the procedure. Local anaesthesia was administered using the inverted "L" technique and 3 to $5 \mathrm{mg} / \mathrm{kg}$ of $2 \%$ lidocaine hydrochloride with a vasoconstrictor. The equipment used for the laparoscopic surgery was a portable setting, with the image capture system, camera, and light emitting diode (LED) connected to a $10-\mathrm{mm}$ optical fibre cable and monitor all coupled to a single device (Telepack Vet Karl Storz Veterinary Endoscopy) and a $\mathrm{CO}_{2}$ insufflator (Karl Storz Veterinary Endoscopy, Stuttgart, Germany) with controlled pressure and temperature (Bouré 2005).

The operation was performed on the side corresponding to the main clinical and ultrasound results; this was the left side only for Bovine 3, whereas the right side was accessed for the other animals. First, pneumoperitoneum was induced with $\mathrm{CO}_{2}$ for better visualisation of the intracavitary environment and to insert the first surgical port with greater security. To create the pneumoperitoneum, the skin was perforated $5 \mathrm{~cm}$ ventral to the L3 vertebra with a $40 \mathrm{x}$ 16-mm hypodermic needle. After this needle was removed, a Veress needle was introduced through the same skin hole for abdominal insufflation. After penetration into the abdomen, insufflation was carried out using $\mathrm{CO}_{2}$ with the pressure maintained at $8 \mathrm{mmHg}$. The needle was removed shortly after access to the abdominal cavity was achieved through the first port, which was accomplished through a 2.5-cm skin incision followed by insertion of an 11-mm EndoTIP cannula (Karl Storz Veterinary Endoscopy) $10 \mathrm{~cm}$ ventral to the L3 vertebra and $10 \mathrm{~cm}$ caudal to the 13 th rib under endoscopic visualisation. The use of pneumoperitoneum before access to the abdominal cavity with EndoTIP improves the safety of the procedure and prevents accidental viscera perforation resulting from viscera adhering to the abdominal wall. After the cavity was reached, an

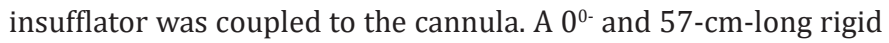
endoscope was introduced through the port accessed by the EndoTIP cannula for visualisation.

During the surgical exploration, if the surgical access was on the left site, the visceral visualisation was in the following sequence: in the cranial view, the lateral wall, spleen, and rumen and in the caudal view, the left ovary, uterus, rectus, caecum, and intestinal loops into the omental bursa. When the surgical access was on the right site, the exploration started with the external sheets of the omental bursa, with the duodenum descendent, in the cranial view, the duodenal flexure, pancreas, pylorus, abomasum, hepatic right lobe, right kidney, omasum and in the caudal view, the right ovary, uterus, rectus, caecum and ascendant colon, and bladder. During exploration, videos and pictures of organs were taken and stored in Telepack ${ }^{\circledR}$.

After the surgical exploration was completed, the pneumoperitoneum was eliminated by compression of the abdomen in the side contralateral to the surgical site, and the skin was sutured using 0.60 -mm polyamine thread with a standard Wolf suture.

The animals received analgesic medication (flunixin meglumine, $2.2 \mathrm{mg} / \mathrm{kg}$, intravenous - IV) before laparoscopy. After surgery, based on the clinical, ultrasonographic, and laparoscopic results, six animals with critical conditions and high cost-associated treatment were euthanised for financial reasons after obtaining the owner's permission (Luna \& Teixeira 2007). Only one animal diagnosed with left abomasal displacement was treated after laparoscopy.

Necropsy. Post-mortem examinations were performed in a necropsy room with a table for large animals approximately 2 hours after death according to a technique adapted from Peleteiro \& Correia (2016).

\section{RESULTS AND DISCUSSION}

The following diseases were diagnosed: traumatic reticuloperitonitis (TRP) (Fig.1-6), paratuberculosis (postmortem diagnosis), displacement of the abomasum, necrotic enteritis with fibrinonecrotic peritonitis and obstruction of the reticulo-omasal orifice followed by ruminal impaction, liver abscess, traumatic reticulosplenitis and abscedative hepatitis, and pneumonia. Laboratory analysis revealed leucocytosis, neutrophilia with inversion of the neutrophil:lymphocyte ratio, and high level of plasmatic fibrinogen.

The main clinical results, with the relative frequency, are shown in Table 1, and the ultrasound diagnosis compared with laparoscopy and post-mortem diagnosis are described in Table 2. For this procedure, the physical restraint with local anaesthesia was sufficient to perform laparoscopy safely, and all animals remained in the standing position during the procedure. The use of a Veress needle was satisfactory for safe and efficient pneumoperitoneum induction without accidental viscera laceration by the needle or during the first trocar insertion. In one animal (Bovine 6), the Veress needle was positioned in the retroperitoneal space during the abdominal insufflation, a technical failure that prevented the complete laparoscopic abdominal exploration; this is a unique complication in this laparoscopic approach.

Ultrasound allowed a conclusive diagnosis of the primary disease ante-mortem only in $44 \%$ of the animals, and laparoscopy only in $11 \%$; however, both allowed the characterisation of peritonitis without a definitive cause. In both situations, clinical and laboratory data facilitated clinical decision making regarding the feasibility of treatment and prognosis and guided the collection of materials when necessary (Braun 2005, Tharwat et al. 2012).

Laparoscopy allowed a conclusive diagnosis of the primary disease ante-mortem in only $11 \%$ of animals, though it did result in only the characterisation of peritonitis without a definitive cause in the other animals. A limitation of laparoscopy through the approach used in the present study is the inability to explore the cranioventral region as well as the structures located more ventrally in the supraomental bursa (Anderson et al. 1993). Laparoscopy with a flexible endoscope was performed in a previous study (Wilson \& Ferguson 1984) to compare clinical presentation with laparoscopic and laparotomy findings for differential diagnosis of TRP. Fibrin tags, turbid PF, and white adhesions of the spleen and abdominal cavity were positive diagnostics for TRP, and 92\% diagnostic accuracy was obtained. In contrast,

Table 1. Clinical findings

\begin{tabular}{lc}
\hline \multicolumn{1}{c}{ Clinical findings } & Relative frequency \\
\hline Apathetic & $55.55 \%(5 / 9)$ \\
Inappetence & $55.55 \%(5 / 9)$ \\
Dehydration & $55.55 \%(5 / 9)$ \\
Fever (above 38.5) & $33.33 \%(3 / 9)$ \\
Tachypnoea (normal 24-36) & $33.33 \%(3 / 9)$ \\
Tachycardia (normal <60) & $55.55 \%(5 / 9)$ \\
Ruminal hypomotility & $77.77 \%(7 / 9)$ \\
Reticulum tests positive & $11.11 \%(1 / 9)$ \\
Intestinal hypomotility & $88.88 \%(8 / 9)$ \\
Pain and/or crepitations during rectal exam & $22.22 \%(2 / 9)$
\end{tabular}



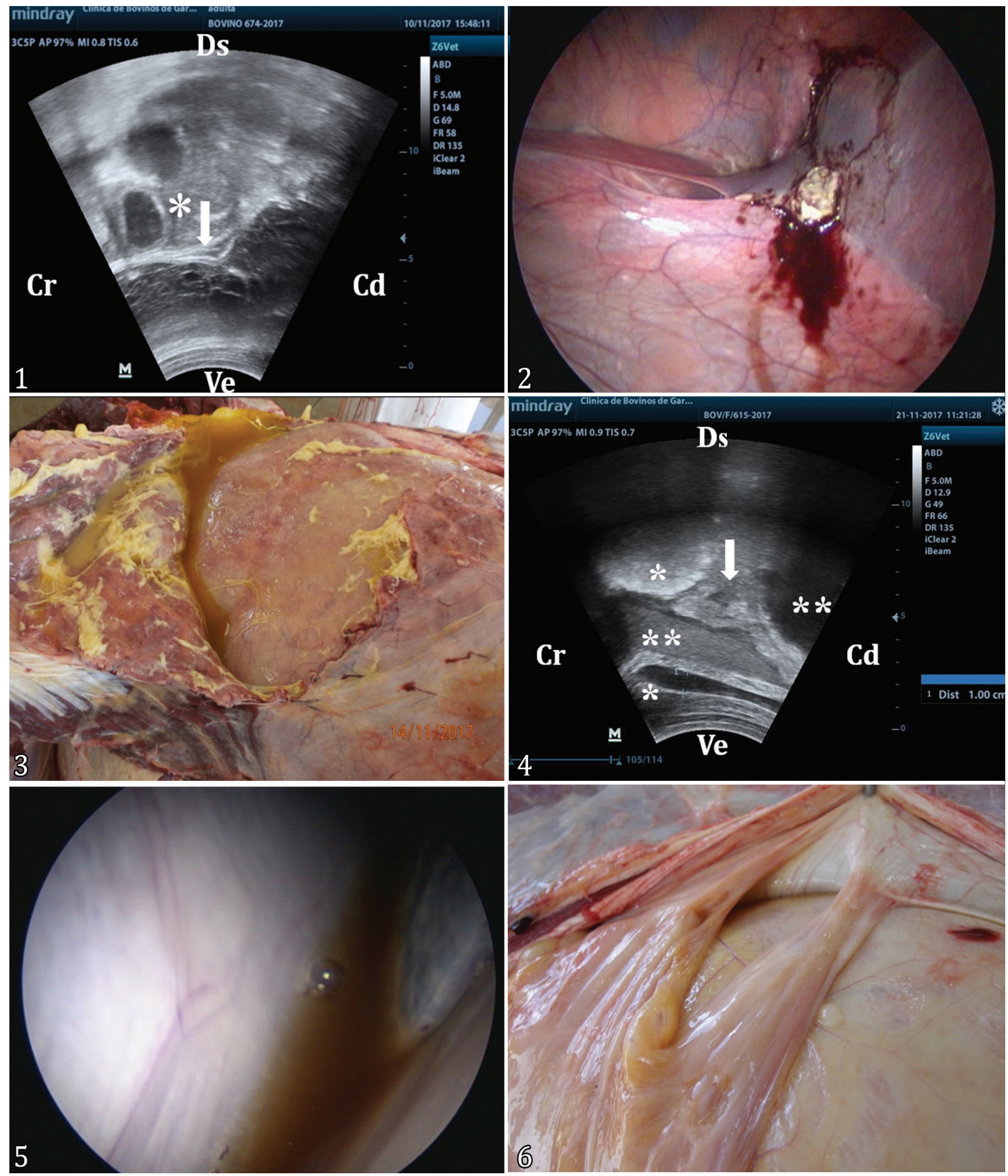

Fig.1-6.Results of abdominal ultrasound, laparoscopic findings, and necropsy findings of Bovines 1 and 5. (1) Serofibrinous peritonitis in the right ventral region of the abdomen with thickening of the supraomental bursa (arrow) and accumulation of exudate $(*)$, dorsal (Ds), ventral (Ve), cranial (Cr), caudal (Cd), Bovine 5. (2) Rupture of a perihepatic abscess involving hepatic adhesions in Bovine 5. (3) Diffuse serofibrinous peritonitis with multiple fibrin tags in Bovine 5. (4) Abscess (arrow) between the reticulum $(*)$ and caudodorsal ruminal sac (**) measuring $1.1 \times 1.36 \mathrm{~cm}$ (arrow) and spleen ( ${ }^{* * *}$ ) in Bovine 5. (5) Turbid peritoneal fluid package between abdominal wall, rumen, and spleen in Bovine 1. (6) Adhesions between abdominal wall and omentum in Bovine 1. 
in the present study, other diseases in addition to TRP were differentially diagnosed, and there was no improvement in pre-test probability; the presence of infections of any site of peritoneal cavity were not considered positively diagnostic. In this situation, combining the technique with ultrasound is necessary to improve clinical decision making (Braun 2005, Tharwat et al. 2012).

In this study, of three patients suffering from TRP (postmortem diagnosis), two were diagnosed by ultrasonography, whereas the specific diagnosis was missed by laparoscopy. This finding contrasts the findings previously observed in human patients regarding the diagnostic accuracy of laparoscopy in investigating pelvic pain (Bharwani \& Jain 2017), acute abdominal pain (Stefanidis et al. 2009, Jamma \& Jadhav 2015), and peritonitis (Agresta et al. 2006) compared with ultrasound and computed tomography. In these human studies, laparoscopy was superior, whereas the opposite was observed in the present study. This difference is possibly associated with the different trocar insertion site, which in humans is ventral, close to the umbilical scar (Agresta et al. 2006), allowing a broader, panoramic view of a more central point. In addition, the proportions of the organs and the location of the intestines inside the omental bursa in cattle differ from those in humans, which limits exploration by rigid endoscopy of the structures contained therein.

Notably, in Bovines 5 and 6, which presented with reticuloperitonitis and necrotic enteritis, respectively, the presence of severe peritonitis with intracavitary gas production led to a reduction in the structural detail of the images obtained by ultrasonography (Braun 2016).

Table 2. Ultrasound and laparoscopic diagnosis compared with final diagnosis based upon surgery or necropsy in nine bovines

\begin{tabular}{cl}
\hline Bovine & \multicolumn{1}{c}{ Ultrasound examination } \\
\hline 1 & $\begin{array}{l}\text { TRP (Reticulum dorsally displaced by a structure of heterogeneous } \\
\text { echogenicity, deformed, and irregularly contoured and fibrin filaments } \\
\text { adhered to the reticulum, rumen, and spleen. The reticulum presented } \\
\text { five unproductive attempts of biphasic contractions in } 3 \mathrm{~min} \text {; the } \\
\text { greatest displacement was } 1 \mathrm{~cm} \text {. Abscess in the liver). }\end{array}$ \\
2 & $\begin{array}{l}\text { Liver abscess (In the most ventral region, liver with a structure } \\
\text { surrounded by a capsule with heterogeneous content ranging from } \\
\text { anechoic to hypoechoic areas, which measured } 6.2 \times 6.7 \mathrm{~cm}) .\end{array}$
\end{tabular}

3 Inconclusive (Discrete irregularity of the abomasal surface. At the height of the 8th and 9th ICS, a volume increase of $4.3 \times 4.3 \mathrm{~cm}$ was observed, with a hyperechoic surface and heterogeneous content composed of hyper- and hypoechogenic areas).

$4 \quad$ Left abomasal displacement (Abomasum observed in the 10th, 9th, and 8th ICS, with gaseous and liquid contents in the ventral region of the organ with abomasal crypts visualised in the middle of the liquid).

5 Diffuse serofibrinous peritonitis (Irregularly contoured reticulum, increased peritoneal fluid and content with heterogeneous echogenicity and echotexture (fibrin) attached to the reticular wall and remaining abdominal organs).

6 Diffuse serofibrinous peritonitis (Irregularly contoured reticulum with heterogeneous and deformed hypoechoic material adhered to the reticular wall. Increased anechoic peritoneal fluid).

7 Focal abscedative peritonitis (Reticulum displaced (by abscess) caudally until the 9th ICS and presenting two biphasic contractions of low amplitude in $3 \mathrm{~min}$. Abscess $18 \mathrm{~cm}$ in diameter adjacent to the abomasum, small amount of fluid, and discrete more echogenic filaments floating (suggestive of fibrin) between the abomasum and the abscess).

8 TRP and abscedative splenitis (Irregularly contoured reticulum, $6 \mathrm{~cm}$ away from the diaphragm by adhesion, presented two attempts of contraction in 3 min but with very small amplitude. Multiple abscesses in the spleen).

9 Abscess in and adjacent to the liver.
Laparoscopic findings (Diagnosis)

Turbid peritoneal fluid only (Inconclusive)

Hyperaemia of the peritoneum in the ventro-lateral region adjacent to the liver, with recent adhesions between the liver and abdominal wall, and petechiae in the mesoduodenum in the cranial flexure (Focal peritonitis adjacent to the liver) Only a slight PF increase (Inconclusive)

Displaced abomasum in the left side between the rumen and the abdominal wall (Left abomasal displacement)

Multiple liver abscesses were observed, which were associated with adhesions between the liver and the abdominal wall and diaphragm, and multiple areas with petechiae and suffusions were also observed (Diffuse serofibrinous peritonitis, with liver abscess)

Hyperaemia of the larger omentum with multifocal petechiae and multiple adhesions between the viscera and abdominal wall (Diffuse serofibrinous peritonitis)

Recent adhesions were observed between the liver, supraomental bursa, mesoduodenum, pancreas, and abdominal wall (Focal peritonitis)

Hyperaemia of the larger omentum and peritoneum with multifocal petechiae (Diffuse peritonitis)

Multiple adhesions between the liver and abdominal wall were found (Perihepatic adhesions)
Post-mortem or surgical diagnosis

TRP with diaphragmatic abscess

TRP with necrotic splenitis, liver and myocardial abscesses

Mesenteric lymphadenomegaly (Paratuberculosis)

Left abomasal displacement (surgical)

Reticulohepatitis with diffuse fibrinopurulent peritonitis and liver abscess

Diffuse necrotic enteritis with fibrinonecrotic peritonitis and obstruction of the reticulo-omasal orifice Liver abscess

TRP and abscedative splenitis

Liver and myocardial abscesses 
Moreover, the use of laparoscopy through the paralumbar cavities allowed visualisation of alterations in the more dorsal structures of the cavity, as well as those caused by peritonitis (Fig.5), even in situations where the primary lesion was distant, such as in the cranioventral region, which can be visualised more easily by ultrasound examination (Fig.4) (Babkine \& Desrochers 2005). In these cases, a ventral surgical approach is recommended with the animal in the dorsal decubitus position, but in the present study, clinical cases were used, abdominal infection was present, and a concern was to avoid the spread of circumscribed infection, and stretch adhesions or exacerbate an abscess. Notably, adhesiolysis is not often feasible in cattle and is labour intensive and may provide insufficient benefit for the risks involved (Anderson et al. 1993, Babkine \& Desrochers 2005). Among the abdominal diseases studied, suspected diffuse peritonitis is the main indication for exploratory laparoscopy (Wittek et al. 2010). Additionally, laparoscopy allowed us to collect PF in one case where collection by ventral abdominal puncture was not successful (Santos et al. 2020).

Although the use of a Veress needle in cattle is not commonly described (Bouré 2005, Kaneko et al. 2015, Robert et al. 2016), this technique was satisfactory for pneumoperitoneum induction in all animals in this study, with no visceral trauma or obstruction of the $\mathrm{CO}_{2}$ flow during the insufflation procedure, and promoted a safer procedure for abdominal access. Adult bovines have substantial skin thickness and resistance, necessitating initial perforation of the skin using a $40 \times 16-\mathrm{mm}$ hypodermic needle, followed by insertion of the Veress needle. The techniques used to confirm the location of the needle tip in the peritoneal cavity were based on the intracavitary negative pressure; however, there are clinical situations in which septic peritonitis is accompanied by intrabdominal gas production, eliminating the possibility of this procedure (Dirksen 1993, Câmara et al. 2010). Insertion of the needle in a more dorsal location relative to the port (Bouré 2005) is intended to reduce the risk of accidental visceral trauma.

The EndoTIP cannula provided rapid and safe access to the peritoneal cavity in all bovines, where the induction of pneumoperitoneum and the thin abdominal wall of the dairy cattle were factors that reduced the possibility of peritoneal detachment and a retroperitoneal approach. The use of $8 \mathrm{mmHg}$ of pressure with $\mathrm{CO}_{2}$ during the surgery allowed the collection of $\mathrm{PF}$ samples as well as satisfactory and safe visceral visualisation and manipulation without discomfort to the animal. This last aspect is very important considering that the surgeries were performed with the animal in the standing position without sedation, and some of them were severely ill. All these measures, in addition to adequate physical restraint, should be taken into account to avoid unexpected decubitus during surgery, a complication that has been described during laparoscopic procedures in cattle that exposes the surgical team, animal, and equipment to unnecessary risks (Fubini \& Ducharme 2017).

The animals used in this study showed signs of apathy, with ruminal and intestinal hypomotility, which are frequent in cattle with digestive disorders due to limitations resulting from adhesions and due to systemic repercussions of the pathophysiology of morbid processes, such as fever and acid-base and hydroelectrolytic changes (Dirksen 1993, Silva Filho et al. 2010).
Necropsy in cases of diffuse severe peritonitis has a fundamental role in diagnosing the primary disease considering the difficulty of complete abdominal visualisation (Anderson et al. 1993, Fecteau 2005). Necropsy enables confirmation of the clinical diagnosis, reveals organic changes that are unnoticed in clinical examinations, allows accurate measurement of the damage caused by the morbid process, and serves as a quality control for the ante-mortem diagnosis given that full agreement between ante- and post-mortem diagnoses ranges from 51.3 to $85.1 \%$ (Wäsle et al. 2017).

\section{CONCLUSION}

Exploratory laparoscopy through the paralumbar fossa is an adjuvant procedure in diagnosing abdominal disorders in cattle, though we suggest that it is not suitable in cases of diseases characterised by focal lesions concentrated in the cranioventral region of the abdomen. Ultrasonography is apparently superior to laparoscopy for diagnosing abdominal digestive disorders in adult cattle. Lesions are more evident when located in the dorsal quadrant of the abdominal cavity. Thus, laparoscopy complements ultrasonography for diagnosing abdominal disorders in cattle.

\section{AUTHOR CONTRIBUTIONS}

Alcantara U.A.A., Rebouças, R.A., and Alonso J.M. contributed to the general study, mainly laparoscopy execution and interpretation. Cajueiro J.F. contributed to the study design, ultrasonography execution, and manuscript preparation. Mendonça C.L. contributed to the study design and execution, laboratory analysis, and interpretation and final approval of the manuscript. Silva J.R.B., Afonso J.A.B., and Rodrigues C.A. contributed to the study design, study execution, and interpretation and final approval of the manuscript.

Acknowledgements.- The authors thank the "Fundação de Amparo à Pesquisa do Estado de São Paulo" (FAPESP) for the financial support granted for the regular project 2016/20066-4 and the "Coordenação de Aperfeiçoamento de Pessoal de Nível Superior" (CAPES) for granting the master's degree scholarship.

Conflict of interest statement.- The authors declare no conflicts of interest related to this work.

\section{REFERENCES}

Agresta F., Ciardo L.F., Mazzarolo G., Michelet I., Orsi G., Trentin G. \& Bedin N. 2006. Peritonitis: laparoscopic approach. World J. Emerg. Surg. 1:9. <https://dx.doi.org/10.1186/1749-7922-1-9> <PMid:16759400>

Anderson D.E., Gaughan E.M. \& St-Jean G. 1993. Normal laparoscopic anatomy of the bovine abdomen. Am. J.Vet. Res. 54(7):1170-1176. <PMid:8368616>

Babkine M. \& Desrochers A. 2005. Laparoscopic surgery in adult cattle. Vet. Clin. N. Am., Food Anim. Pract. 21(1):251-279. <https://dx.doi.org/10.1016/j. cvfa.2004.12.003> <PMid:15718095>

Bharwani H. \& Jain M. 2017. Comparing role of laparoscopy, ultrasound and clinical examination in pelvic pain. Int. J. Reprod. Contracept. Obstet. Gynecol. 6(7):2983-2989. <https://dx.doi.org/10.18203/2320-1770. ijrcog20172921>

Bleul U., Hollenstein K. \& Kähn W. 2005. Laparoscopic ovariectomy in standing cows. Anim. Reprod. Sci. 90(3/4):193-200.<https://dx.doi.org/10.1016/j. anireprosci.2005.01.022><PMid:16298270> 
Bouré L. 2005. General principles of laparoscopy. Vet. Clin. N. Am., Food Anim. Pract. 21(1):227-249. <https://dx.doi.org/10.1016/j.cvfa.2004.12.002> $<$ PMid:15718094>

Braun U. 2005. Ultrasound as a decision-making tool in abdominal surgery in cows. Vet. Clin. N. Am., Food. Anim. Pract. 21(1):33-53. <https://dx.doi. org/10.1016/j.cvfa.2004.11.001><PMid:15718086>

Braun U. 2016. Ascites in cattle: ultrasonographic findings and diagnosis. Vet. Clin. N. Am., Food Anim. Pract. 32(1):55-83.<https://dx.doi.org/10.1016/j. cvfa.2015.09.004> <PMid:26922112>

Câmara A.C.L., Afonso J.A.B., Costa N.A., Mendonça C.L., Souza M.I. \& Borges J.R.J. 2010. Fatores de risco, achados clínicos, laboratoriais e avaliação terapêutica em 36 bovinos com deslocamento de abomaso. Pesq. Vet. Bras. 30(5):453-464. <https://dx.doi.org/10.1590/S0100-736X2010000500014>

Chiesa O.A., von Bredow J., Smith M. \& Thomas M. 2009. One-port video assisted laparoscopic kidney biopsy in standing steers. Res. Vet. Sci. 87(1):133-134. <https://dx.doi.org/10.1016/j.rvsc.2008.10.016><PMid:19081120>

Dirksen G. 1993. Sistema digestivo, p.166-240. In: Gründer H. \& Stöber M. (Eds), Rosemberger, Exame Clínico dos Bovinos. 3ae ed. Guanabara Koogan, Rio de Janeiro.

Fecteau G. 2005. Management of peritonitis in cattle. Vet. Clin. N. Am., Food Anim. Pract. 21(1):155-171. <https://dx.doi.org/10.1016/j.cvfa.2004.12.007> $<$ PMid:15718091>

Fubini S.L. \& Ducharme N. 2017. Farm Animal Surgery. 2nd ed. Elsevier, St. Louis, p.40.

Hirsbrunner G., Eicher R., Meylan M. \& Steiner A. 2001. Comparison of thelotomy and theloscopic triangulation for the treatment of distal teat obstructions in dairy cows - a retrospective study (1994-1998). Vet. Rec. 148(26):803805. <https://dx.doi.org/10.1136/vr.148.26.803><PMid:11467607>

Jamma S. \& Jadhav M.B. 2015. Study of role of laparoscopy in acute abdomen. Int. J. Biomed. Res. 6(6):395-398. <https://dx.doi.org/10.7439/ijbr>

Janowitz H. 2001. [Laparoscopic reposition and fixation of the left displaced abomasum in cattle]. Tierarztl Prax Ausg G Grosstiere Nutztiere. 26(6):308-313. <PMid:9857408>

Kaneko Y., Torisu S., Kitahara G., Hidara Y., Satoh H., Asanuma T., Mizutani S., Osawa T. \& Naganobu K. 2015. Laparoscopic cryptorchidectomy in standing bulls. J. Vet. Med. Sci. 77(5):631-635. <https://dx.doi.org/10.1292/ jvms.14-0587><PMid:25715955>

Lau W.Y., Leow C.K. \& Li A.K.C. 1997. History of endoscopic and laparoscopic surgery. World J. Surg. 21(4):444-453. <https://dx.doi.org/10.1007/ pl00012268> <PMid:9143579>

Luna S.P.L. \& Teixeira M.W. 2007. Eutanásia: considerações éticas e indicações técnicas. Revta CFMV 13:60-69.

Mulon P., Babkine M. \& Desrochers A. 2006. Ventral laparoscopic abomasopexy in 18 cattle with displaced abomasum. Vet. Surg. 35(4):347-355. <https:// dx.doi.org/10.1111/j.1532-950X.2006.00156.x><PMid:16756615>
Peleteiro M.C. \& Correia J. 2016. Técnica de necrópsia de ruminantes, p.6779. In: Peleteiro M.C., Silva J.F., Dias-Pereira P., Carvalho T., Faustino A., Correia J., Pissarra H. \& Stilwell G. (Eds), Manual de Necrópsia Veterinária. Lidel, Lisboa.

Perotta J.H., Ollhoff R.D., Lisboa J.A.N., Dornbusch P.T., Dÿck H.R., Teider Junior P.I., Vieira N. \& Barros Filho I.R. 2017. One-step laparoscopy for the correction of left abomasal displacement in high-yielding Holstein dairy cows. Semina, Ciênc. Agrárias 38(3):1313-1322. <https://dx.doi. org/10.5433/1679-0359.2017v38n3p1313>

Robert M., Touzot-Jourde G., Nikolayenkova-Topie O., Cesbron N., Fellah B., Tessier C. \& Gauthier 0. 2016. Laparoscopic evaluation of umbilical disorders in calves. Vet. Surg. 45(8):1041-1048. <https://dx.doi.org/10.1111/ vsu.12559><PMid:27685954>

Santos J.F., Rego R.O., Afonso J.A.B., Soares P.C. \& Mendonça C.L. 2020. Biomarcadores sanguíneos e no líquido peritoneal de bovinos acometidos com enfermidades intestinais e reticulates traumáticas. Ciênc. Anim. Bras. 20(1):1-16. <https://dx.doi.org/10.1590/1809-6891v21e-50941>

Silva Filho A.P., Afonso J.A.B., Souza J.C.A., Costa N.A. \& Mendonça C.L. 2010. Análise clínica e patológica em 20 casos de intussuscepção em bovinos. Vet. Zootec. 17(3):421-430.

Silva M.A.M. 2015. Formação de aderências intraperitoneais após procedimentos cirúrgicos convencionais e laparoscópicos, p.21-37. In: Brun M.V. (Ed.), Videocirurgia em Pequenos Animais. Roca, Rio de Janeiro.

Stefanidis D., Richardson W., Chang L., Earle D.B. \& Fanelli R.D. 2009. The role of diagnostic laparoscopy for acute abdominal conditions: an evidencebased review. Surg. Endosc. 23(1):16-23. <https://dx.doi.org/10.1007/ s00464-008-0103-x><PMid:18814014>

Tharwat M., Abdelaal A., Oikawa S. \& Floeck M. 2012. Ante mortem diagnosis of mesothelioma in a cow using ultrasonography and ultrasound-guided biopsy. Wien Tierarztl. Monatsschr. 99:163-168.

Van Leeuwen E., Janowitz H. \& Willemen M.A. 2000. Laparoscopic treatment of left displaced abomasum. Cattle Pract. 8(4):363-365.

Wäsle K., Pospischil A., Hässig M., Gerspach C. \& Hilbe M. 2017. The postmortem examination in ruminants and its possible benefit to ruminant clinical medicine. J. Comp. Pathol. 156(2/3):202-216. <https://dx.doi. org/10.1016/j.jcpa.2017.01.003> <PMid:28213989>

Wilson A.D. \& Ferguson J.G. 1984. Use of a flexible fiberoptic laparoscope as a diagnostic aid in cattle. Can. Vet. J. 25(6):229-234. <PMid:17422411>

Wittek T., Grosche A., Locher L., Alkaassem A. \& Fürll M. 2010. Biochemical constituents of peritoneal fluid in cows. Vet. Rec. 166(1):15-19. <https:// dx.doi.org/10.1136/vr.b5584><PMid:20045853>

Wittek T., Locher L.F., Alkaassem A. \& Constable P.D. 2009. Effect of surgical correction of left displaced abomasum by means of omentopexy via right flank laparotomy or two-step laparoscopy-guided abomasopexy on postoperative abomasal emptying rate in lactating dairy cows. J. Am. Vet. Med. Assoc. 234(5):652-657. <https://dx.doi.org/10.2460/javma.234.5.652> $<$ PMid:19250045> 